\title{
Origin of life: LUCA and extracellular membrane vesicles (EMVs)
}

\author{
S. Gill' and P. Forterre ${ }^{2}$ \\ ${ }^{1}$ Institute for Integrative Biology of the Cell (I2BC), Biologie Cellulaire des Archées (BCA), CEA, CNRS, Université Paris- \\ Sud, 91405 Orsay cedex, France e-mail: sukhi.gill@i2bc.paris-saclay.fr \\ ${ }^{2}$ Institut Pasteur, Unité de Biologie Moléculaire du Gène chez les Extrêmophiles, Département de Microbiologie, F75015 \\ Paris, France
}

\begin{abstract}
Cells from the three domains of life produce extracellular membrane vesicles (EMVs), suggesting that EMV production is an important aspect of cellular physiology. EMVs have been implicated in many aspects of cellular life in all domains, including stress response, toxicity against competing strains, pathogenicity, detoxification and resistance against viral attack. These EMVs represent an important mode of inter-cellular communication by serving as vehicles for transfer of DNA, RNA, proteins and lipids between cells. Here, we review recent progress in the understanding of EMV biology and their various roles. We focus on the role of membrane vesicles in early cellular evolution and how they would have helped shape the nature of the last universal common ancestor. A membrane-protected microenvironment would have been a key to the survival of spontaneous molecular systems and efficient metabolic reactions. Interestingly, the morphology of EMVs is strongly reminiscent of the morphology of some virions. It is thus tempting to make a link between the origin of the first protocell via the formation of vesicles and the origin of viruses.
\end{abstract}

Received 1 June 2015, accepted 8 July 2015, first published online 28 August 2015

Key words: extracellular membrane vesicles (EMVs), LUCA, origin of life, viruses and protocells.

\section{Extracellular membrane vesicles (EMVs) in the three domains}

The secretion of EMVs from cell surfaces is a universally conserved process that occurs in eukaryotes, bacteria and archaea (Raposo \& Stoorvogel 2013). Although initially dismissed as 'cellular dust' extracellular vesicles have emerged as important mediators of inter-cellular communication between cells from all three domains.

These spherical structures are known to contain a variety of molecules including proteins, lipids and nucleic acids. Their diverse biological functions have been extensively documented (see Table 1). The list of functions attributed to EMVs includes binding and delivery of nucleic acids, transport of virulence factors, ridding the cell of toxic envelope proteins and tumorigenesis (Deich \& Hoyer 1982; Dorward et al. 1989; Kadurugamuwa \& Beveridge 1997; Kesty et al. 2004; Renelli et al. 2004; McBroom \& Kuehn 2007; Valadi et al. 2007; Soler et al. 2008; Aldick et al. 2009; Ellis \& Kuehn 2010; Camussi et al. 2011; Rak \& Guha 2012; Gaudin et al. 2013).

The origin, nature and features of EMVs are diverse, and at present there is no consensus on the nomenclature of cellderived vesicles, with many names being used interchangeably in the literature (Gould \& Raposo 2013). This is largely due to an incomplete understanding of extracellular vesicle biogenesis, inconsistencies in extracellular vesicle purification protocols and a lack of detailed vesicle characterization.

\section{EMVs in eukaryotes}

EMVs in eukaryotes have been classified from anywhere between 2 and 6 groups based either on their cellular origin, biological function or method of formation (Cocucci et al. 2009; Théry et al. 2009; Beyer \& Pisetsky 2010; Mathivanan et al. 2010). Based on their mode of biogenesis, eukaryotic EMVs can be classified into three main groups: microvesicles $(50-1000 \mathrm{~nm})$, exosomes $(40-100 \mathrm{~nm})$ and apoptotic bodies (500-2000 nm) (El Andaloussi et al. 2013). Here we focus on microvesicles and exosomes as these two groups are common to all classifications. Microvesicles are formed by budding off from the plasma membrane whereas exosomes are derived from the endolysosomal pathway. The cargoes of both EMV types include cytoplasmic proteins, lipid raft-interacting proteins and RNAs (mRNA, microRNA and other non-coding RNAs) (El Andaloussi et al. 2013). Through transfer of their molecular contents, EMVs are capable of altering the function of recipient cells.

EMVs have been identified in body fluids such as serum, saliva, amniotic fluid, synovial fluid, breast milk and urine (Pisitkun et al. 2004; Keller et al. 2007; Lakkaraju \& Rodriguez-Boulan 2008; Kosaka et al. 2010; Michael et al. 2010). Increasing evidence suggests that both exosomes and microvesicles play a fundamental biological role in the regulation of normal physiological processes (Raposo et al. 1996; Del Conde et al. 2005; Ratajczak et al. 2006; Gatti et al. 2011). The 
Table 1. Overview of the main characteristics of different types of EMVs from the three domains of life (table adapted from van der Pol et al. 2012; El Andalousi et al. 2013)

\begin{tabular}{|c|c|c|c|c|}
\hline & Vesicle type & Origin & Size & Contents \\
\hline \multirow[t]{3}{*}{ Eukaryotes } & Exosomes & Endolysosomal pathway & $40-120 \mathrm{~nm}$ & $\begin{array}{l}\text { mRNA, microRNA (miRNA); cytoplasmic and membrane } \\
\text { proteins including receptors and major histocompatibility } \\
\text { complex (MHC) molecules }\end{array}$ \\
\hline & Micro vesicles & $\begin{array}{l}\text { Cell surface; outward } \\
\text { budding of cell membrane }\end{array}$ & $50-1000 \mathrm{~nm}$ & $\begin{array}{l}\text { mRNA, miRNA, non-coding RNAs, cytoplasmic proteins } \\
\text { and membrane proteins. }\end{array}$ \\
\hline & Apoptosis & Cell surface of all cell types & $500-2000 \mathrm{~nm}$ & Nuclear fractions, cell organelles, histones and DNA. \\
\hline \multirow[t]{2}{*}{ Bacteria } & Extra cellular vesicles & Cytoplasmic membrane & $20-250 \mathrm{~nm}$ & Cytosolic proteins \\
\hline & $\begin{array}{l}\text { Outer membrane } \\
\text { vesicles }\end{array}$ & Outer membrane & $20-300 \mathrm{~nm}$ & $\begin{array}{l}\text { Lipo polysaccharide; phospholipids; nucleic acids, cytosolic } \\
\text { or inner membrane proteins; OmpA in E. coli. }\end{array}$ \\
\hline Archaea & Membrane vesicles & Cytoplasmic membrane & $50-230 \mathrm{~nm}$ & $\begin{array}{l}\text { In Sulfolobus: endosomal sorting complex required for } \\
\text { transport (ESCRT)I, ESCRT-II, Vps4, vWA, thiosulfate } \\
\text { sulphur transferase, flotillin, disulphide oxidoreductase, } \\
\text { S-layer proteins and archaeal tetraether lipids. } \\
\text { In Thermococcales: nucleic acids and proteins. }\end{array}$ \\
\hline
\end{tabular}

release of EMVs, is also enhanced in disease processes such as cancer (Inal et al. 2013). The novel discoveries in the field of EMVs, especially in multicellular eukaryotes have led to the creation of an international society for the study of extracellular vesicles and the creation of two new journals.

\section{EMVs in bacteria}

For many decades the formation of EMVs in prokaryotes was solely focused on bacteria (Kuehn \& Kesty 2005; Ellis \& Kuehn 2010; Kulp \& Kuehn 2010). In bacteria with double membranes (referred to as diderm bacteria) they are generally derived from the outer membrane (OM) which is distinct from the cytoplasmic membrane, and are referred to as OMVs (Kulp \& Kuehn 2010). During the growth the OM 'blebs' outwards and pinches off, forming vesicles $(20-250 \mathrm{~nm})$ that are spherical portions of OM with lumenal periplasmic content. Thus, the composition of OMVs reflects components of the OM and periplasm, for example, soluble proteins, integral membrane proteins, lipoproteins and glycolipids (Beveridge 1999; Horstman \& Kuehn 2000; Schooling et al. 2009). OMVs are potent virulence factors of pathogenic diderm bacteria. These vesicles contain toxins, DNA, immunomodulatory compounds, communication factors and adhesins, and have been associated with cytotoxicity, bacterial attachment, intercellular DNA transfer and invasion (Dorward et al. 1989; Kuehn \& Kesty 2005; Ellis \& Kuehn 2010; Maldonado et al. 2011; Brown et al. 2014). Increased vesiculation has been linked to bacterial stress and may play a role in carrying away toxic compounds, phages or unfolded proteins after exposure to stressful conditions (McBroom \& Kuehn 2007; Macdonald \& Kuehn 2013).

A new type of membrane vesicle was recently described for the Antarctic bacterium Shewanella vesiculosa M7T. These vesicles are referred to as outer-inner membrane vesicles (O-IMVs) and have a more complex double-layer structure. The protrusion of both outer and plasma membranes pulls cytoplasmic components, such as DNA and adenosine triphosphate (ATP), into the vesicles. Further studies confirmed that
O-IMVs are also secreted by diderm pathogenic bacteria such as Neisseria gonorrhoeae, Pseudomonas aeruginosa PAO1 and Acinetobacter baumannii AB41. The authors propose that these O-IMVs may be involved in lateral gene transfer and the transfer of cytoplasmic proteins (Pérez-Cruz et al. 2013, 2015).

Planctomycetes form a distinct phylum of the domain bacteria and possess unusual features such as intracellular compartmentalization and proteinaceous cell walls (Lee et al. 2009). Cells of the genus Gemmata also contain a membranebound nucleoid resembling the eukaryotic nucleus. In addition, an ability to take up proteins from the external medium through a process that is associated with internal vesicle formation was recently demonstrated for Gemmata obscuriglobus and is reminiscent of eukaryotic endocytosis (Lonhienne et al. 2010; Fuerst \& Sagulenko 2011). Electron tomography of $G$. obscuriglobus cells highlighted vesicle-like structures in the periplasm. Some of these vesicle-like structures were connected to each other, forming a continuous membrane organization within the periplasm. In addition, these vesicles contain ribosomes, suggesting continuity with the cytoplasm.

More recently EMVs have been observed in bacteria lacking an OM (referred to as monoderm bacteria) from the phylum Firmicutes. EMVs produced by these bacteria are derived from the cytoplasmic membrane and are 20-250 $\mathrm{nm}$ in diameter (Lee et al. 2009; Schrempf et al. 2011). It has been suggested that the vesicles produced by monoderm bacteria are like their diderm counterparts, involved in pathogenesis (Rivera et al. 2010; Prados-Rosales et al. 2011). Enzymes involved in peptidoglycan degradation, antibiotic degradation, virulence factors (anthrolysin, anthrax toxin components, coagulases, hemolysins and lipases) and immunologically-active compounds have been identified in these vesicles (Marsollier et al. 2007; Lee et al. 2009; Rivera et al. 2010; Gurung et al. 2011; Prados-Rosales et al. 2011; Thay et al. 2013; Brown et al. 2014).

It has been shown that bacteria, produce EMVs not only in the laboratory but also in biofilms and during infections (Schooling \& Beveridge 2006; Deatherage \& Cookson 2012). However, until recently the presence of EMVs in natural 
environments has been largely ignored. A recent study by Biller et al. (2014) highlighted the abundance of bacterial vesicles, from the marine phototrophic bacteria Prochlorococcus, in marine ecosystems as well as in the laboratory. The authors succeeded in isolating EMVs from two very different ocean samples, with concentrations ranging from $10^{5}$ to $10^{6}$ vesicles $\mathrm{ml}^{-1}$ of sea water.

These findings have important implications for microbial ecology as vesicles associated with DNA can mimic viral particles in epifluorescence microscopy (Forterre et al. 2013). The presence of abundant membrane vesicles besides true virions could explain the presence of bacterial sequences in environmental viromes. Moreover, since membrane vesicles can also contain viral genomes, they could even contribute to the viral component of viromes. Discriminating between virions and vesicles (some of them containing viral or plasmid DNA) appears to be a major challenge for future studies in viral ecology (Soler et al. 2015). In Eukarya, some virus-infected cells produce EMVs harbouring viral proteins and/or mRNA and microRNA (Pegtel et al. 2010; Meckes \& Raab-Traub 2011). This suggests that viral vesicles (containing genomic DNA or RNA) could also exist in Eukarya.

Physiological interactions between EMVs and viruses have also been reported recently. As early as 1978, work done by Loeb et al. demonstrated a dramatic increase in OM production and release in the presence of T4 phage in Escherichia coli (Loeb \& Kilner 1978). More recently, Manning and Kuehn showed that co-incubation of T4 bacteriophage and OMVs showed fast and irreversible binding. The efficiency of T4 infection was significantly reduced by the formation of complexes with the OMVs suggesting that EMVs can protect bacteria against viral infection by serving as traps for virions (Manning \& Kuehn 2011). In addition, Biller et al. demonstrated that when purified Prochlorococcus vesicles were mixed with the cyanophage (PHM-2) the phage bound to vesicles. Intriguingly many vesicle- attached phage had a shortened stalk and altered capsid staining density, suggesting that they had injected their DNA into the vesicle (Biller et al. 2014).

\section{EMVs in Archaea}

Most archaeal species are monoderm with a cytoplasmic membrane surrounded by a crystalline protein $\mathrm{S}$ layer (Ellen et al. 2010; Albers \& Meyer 2011). Only a few archaeal groups are diderm (Klingl 2014). The only diderm archaea that has been studied in detail is Ignicoccus hospitalis (Huber et al. 2002; Küper et al. 2010). The volume of Ignicoccus inter-membrane space can be large (20-1000 nm) and contains numerous vesicles that bud from the inner membrane and fuse with the $\mathrm{OM}$ (Näther \& Rachel 2004).

Curiously, all archaea that possess a double membrane are found in close association with other organisms (Archaea, Bacteria and Eukarya) (Perras et al. 2014). Ignicoccus hospitalis usually harbours several cells of the tiny archaeon Nanoarchaeum equitans on its surface (Huber et al. 2002). $N$. equitans has the smallest known genome size for an archaeon $(0.49 \mathrm{Mb})$ and cannot synthesize many essential components, including lipids (Waters et al. 2003). It is assumed that these components could be delivered from the cytoplasm of I. hospitalis to $N$. equitans via vesicles that reach the $\mathrm{OM}$ at the level of the symbiont attachment.

Monoderm archaea also produce EMVs. The earliest reports for archaeal EMVs came from the studies carried out on crenarcheal Sulfolobus islandicus (Prangishvili et al. 2000). These vesicles, 90-230 $\mathrm{nm}$ in diameter and coated with an S layer, were shown to be associated with an antimicrobial protein, termed 'sulfolobicin', that inhibits the growth of related Sulfolobus species. Proteomic analyses showed that the lipid and protein profiles of parent cells and secreted vesicles were different (Ellen et al. 2009).

A study carried out to screen for novel viruses among the euryarchaeal order of Thermococcales revealed that most of the strains tested released small spherical vesicles (Soler et al. 2008; Gaudin et al. 2013; Marguet et al. 2013). These vesicles $(50-150 \mathrm{~nm})$ are produced by a protruding of the cell envelope along with the S layer and frequently form rows of EMVs ressembling nanopods or nanotubes observed in Bacteria and sometimes can connect cells together (Marguet et al. 2013).

A closer look at the protein profiles of EMVs from two species of Thermococcales, Thermococcus gammatolerans and Thermococcus kodakaraensis showed that both EMVs and cell membranes from the same species have a similar composition. This is in contrast to the results obtained by Ellen et al. (2009) for Sulfolobus. The major protein present in cell membranes and EMVs of both species is the oligopeptide binding protein OppA (Gaudin et al. 2013) which is also found in Sulfolobus EMVs (Ellen et al. 2009). EMVs produced by Thermococcales often have genomic DNA associated with them (Soler et al. 2008). It appears that the DNA is afforded a degree of protection by the vesicles and is more resistant to thermodenaturation. This could be vital for horizontal gene transfer in hyperthermophilic archaea, which thrive in temperatures that are not so kind to DNA. The group went on to demonstrate that EMVs transfer DNA between cells using the genetically tractable strain $T$. kodakaraensis KUW1 (Gaudin et al. 2013). Interestingly, EMVs produced by Thermococcus nautili harbour the genome of the plasmid pTN1 and of a defective virus named pTN3 suggesting a possible role in gene transfer between species and generation of new viral forms (Soler et al. 2011; Gaudin et al. 2014).

\section{Viruses and EMVs}

Interestingly, the morphology of EMVs is strongly reminiscent of the morphology of some virions. It is thus tempting to make a link between the origin of the first protocell via the formation of vesicles and the origin of viruses. The origin of viruses is a fascinating and important topic as metagenomic analyses have shown that viral genomes represent the major source of genetic information in the biosphere (Suttle 2005; Rohwer \& Thurber 2009; Kristensen et al. 2010). Viruses are extremely diverse and each one of the three domains of life is associated with a specific ensemble of viral lineages (Pina et al. 2011; Forterre et al. 2014). Viruses are also very ancient, predating the last 
universal common ancestor (LUCA), since some major viral lineage defined by homologous capsid proteins and packaging ATPases are present in these three ensembles (Abrescia et al. 2012). Three types of hypotheses have been put forward to explain this origin: the 'virus first' hypothesis in which viruses originated before cells, the 'regression hypothesis', in which cells or proto-cells evolved into virions by regressive evolution and the 'escape hypothesis', in which fragments of cellular genomes (either from prokaryotes or eukaryotes) became infectious (Forterre 2006, 2010). Forterre and Krupovic recently reevaluated the escape hypothesis (Forterre \& Krupovic 2012). The updated version of this hypothesis proposes that viruses originated by transformation of ancient ribocells (cell encoding ribosome and dividing by binary fission) into a ribovirocell, still dividing but producing virions carrying selfish RNA replicons are capable of infecting other ribocells, and later on into virocells (cell producing virions) killing their host ribocells. In the classical version of the escape hypothesis, these ribocells are confused with modern cells (prokaryotes or eukaryotes). In the updated version of the escape hypothesis, these ribocells were ancestral RNA-based cells that antedated LUCA (refer Fig. 1). Furthermore, in the classical version of the escape hypothesis, the focus was on the viral genome, with the origin of virions put aside; the 'modern escape hypothesis' focuses on the virion (Forterre \& Krupovic 2012). The origin of viruses should not be confused with the origin of viral genomes per se, the latter being in fact the history of replicons. To understand the origin of viruses, one should focus on the origin of the mechanisms of virion production by virocells (how they are formed, excreted from the cell and how they can transfer their genomic information into cells). Viral genomes may have originated from ancestral selfish replicons present in ancient ribocells and virions from micro-compartments, nucleoprotein complexes or EMVs present in ancient ribocells (Forterre \& Krupovic 2012).

The production of EMVs by ancient cells or proto-cells could have thus played a role in the origin of some of the very first viral lineages before LUCA (Jalasvuori \& Bamford 2008). Intriguingly, vesicles have many characteristics in common with enveloped viruses including biophysical properties, formation and uptake by cells. It is clear that some viruses utilize vesicle secretion pathways during infection. For example, retroviruses recruit several elements from the vesicle biogenesis pathways for functional virus release suggestive of a possible viral origin of the microvesicle system or perhaps of an evolutionary conserved system of virus-vesicle co-dependence (Izquierdo-Useros et al. 2011). Are EMVs predecessors of viruses or do the viruses merely exploit the same cellular machinery? (Gould et al. 2003; Pelchen-Matthews et al. 2004). Analysis of EV cargo revealed that many of the molecules found have been implicated in virus binding and entry (György et al. 2011). The diversity of EMV populations and components suggests that EMVs enter cells through various mechanisms similar to the multiple pathways identified for viruses (Marsh \& Helenius 2006). Understanding the interplay between viruses and EMVs could shed some light on the origin of EMVs and or origin of viruses. Our current mechanistic understanding of EMV biology and function, especially in regard to virus infection, is in its infancy. However, the obviously broad biological, medical and evolutionary implications of EMVs make them a significant and exciting area of research.

\section{LUCA, the origin of life and EMVs}

The fact that all cells tested from the three domains of life produce EMVs suggests that this is an ancient process that possibly dates back to the LUCA, or beyond. LUCA is the most recent organism from which all modern cells derive. LUCA should not be confused with the first cell, but was the product of a long period of evolution. Being the 'last' means that LUCA was preceded by a long succession of older 'ancestors.' A plethora of cellular lineages that have left no descendants today may have existed before LUCA. It is important to consider that many of these were probably still present at the time of LUCA, and some have probably even coexisted for some time with its descendants, possibly contributing via horizontal gene transfer to some traits present in modern lineages (Forterre \& Gribaldo 2007).

Due to advances in comparative genomics we can infer some of the characteristics of LUCA by comparing what present-day organisms have in common. The key assumption is that genes shared by many diverse extant species are most likely to be inherited from their common ancestor. The 'core' set of genes is very small and nearly all of them encode proteins involved in translation and the core transcription machinery. If the genes for rRNAs and tRNAs are included, the universal set comprises about 100 genes (Harris et al. 2003; Koonin 2003; Charlebois \& Doolittle 2004; Delaye et al. 2005). Beside proteins involved in translation and transcription, this small gene set includes a few critical proteins involved in the makeup of membranes, such as membrane bound ATPases, signal recognition particles involved in the translation of membrane proteins and proteins involved in protein secretion. It is thus now clear that LUCA was a cellular organism that already harboured a sophisticated translation apparatus and had a cytoplasmic membrane (Pereto et al. 2004; Jekely 2006; Forterre \& Gribaldo 2007).

In living cells today, cell membranes perform varied roles despite the fact that they are primarily considered necessary to partition cells. These roles include: energy transduction, nutrient and ion transport, signal transduction and certain metabolic reactions. The latter include the synthesis of the membrane lipids themselves to allow growth of the bilayers in different cellular compartments (Segré et al. 2001). On the early Earth, they also provided 'micro-environments' enabling the confinement of molecular information and organic resources essential for the beginning of cellular life. This confinement helped to prevent leakage, concentrate substrates to promote reactions and isolate successful RNA replicators from unsuccessful ones (Koch 1985; Deamer 1997; Segré et al. 2001). The RNA world would be difficult to achieve from simple organic molecules dissolved in the primordial soup (Joyce 1991; Deamer et al. 2002). Random concentration of the molecules may have occurred due to processes such as evaporation, eutectic freezing, or adsorption to mineral 


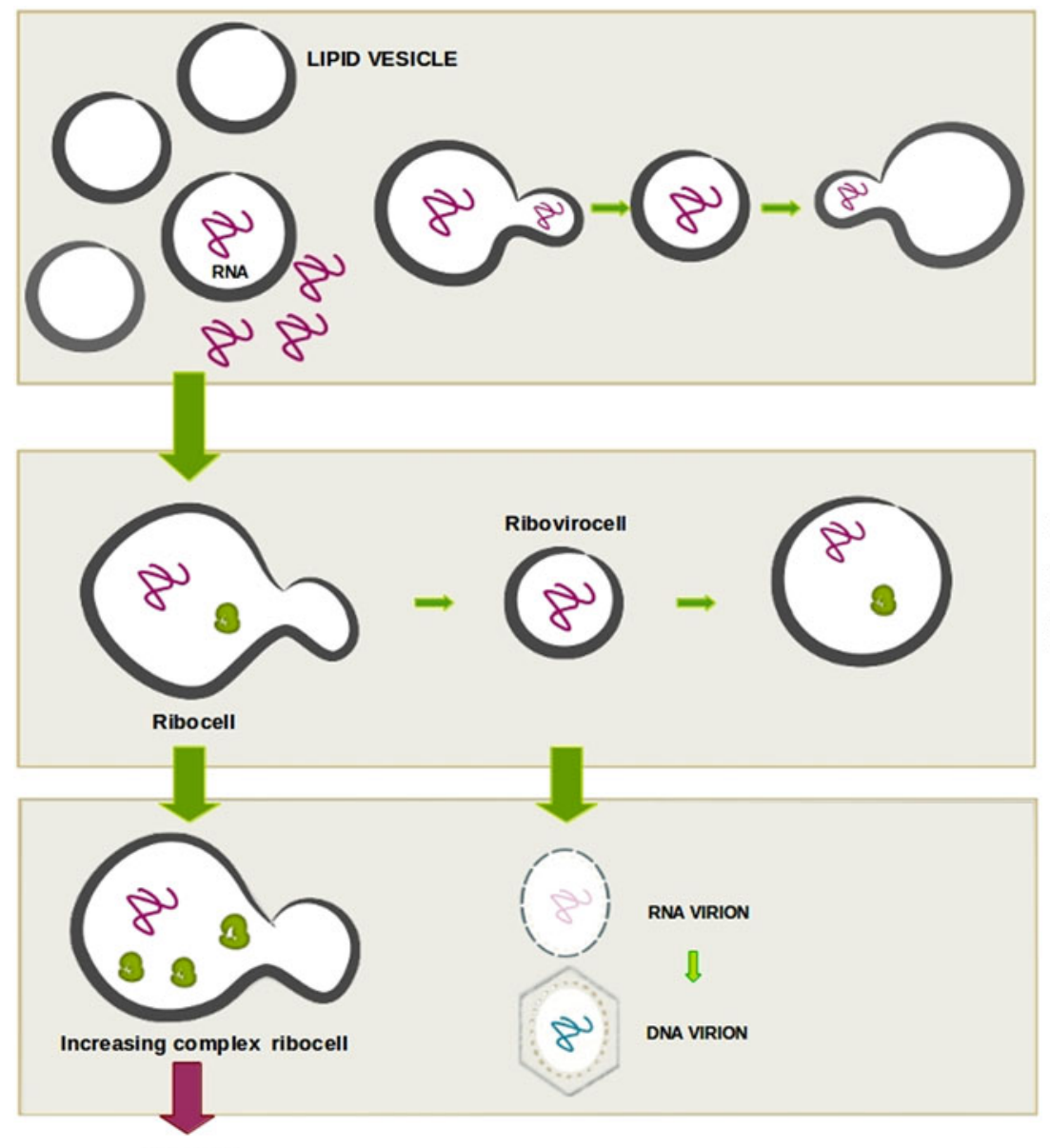

\section{EARLY PROTOCELLS}

Lipid vesicles provided "micro environments" concentrating molecular information (RNA) and organics resources essential for the beginning of cellular life.

Ancient protocells. undergo shear-induced division due to an increased fatty acid concentration (evaporation in arid. vapor-dominated geothermal fields).

\section{LUCA}

\section{RIBOCELLS \& RIBOVIROCELLS}

Cells encoding ribosomes (shown in green) Transformation of ribocells to ribovirocells (producing virions) carrying selfish RNA replicons capable of infecting other ribocells.

\section{INCREASING COMPLEXITY}

Increasingly complex replication systems and membranes. These ribocells were ancestral RNAbased cells that antedated LUCA.

Appearance of virions. firstly transferring RNA genomes and later DNA.

Fig. 1. Role of membrane vesicles in early cellular evolution and how they would have helped shape the nature of LUCA.

surfaces (Wächtershäuser 1988; Stribling \& Miller 1991; Robertson \& Miller 1995; Ferris et al. 1996; Kanavarioti et al. 2001; Sowerby \& Petersen 2002). However, these processes on their own would be thermodynamically inefficient to account for the origin of life beyond the initial stages (Deamer et al. 2002).

Since compartmentalization is a key issue in the early evolution of life many researchers have tried to reconstruct the habitats of the earliest life forms where, under natural conditions, small cell-like compartments could be formed in large numbers over an extended period of time. Mulkidjanian et al. combined geochemical evidence with ionic composition of the modern cells, with a particular emphasis on their universal preference for $\mathrm{K}+$ ions over $\mathrm{Na}+$ ions. They suggest that the first cells could have emerged at inland geothermal fields within ponds of condensed and cooled geothermal vapour (Mulkidjanian et al. 2012).

Schreiber et al. presented a model for the origin of life in tectonic fault systems in the continental crust (Schreiber et al. 2012). These vast networks (from sub-mm to several meters) of interconnected cracks and cavities are mainly filled with water and carbon dioxide. They also provide a wide variety of hydrothermal chemistry and numerous catalytic surfaces and thus may offer ideal reaction conditions for prebiotic chemistry (Schreiber et al. 2012). The authors also predicted that vesicle formation is expected to occur in these tectonic fault zones at a depth where pressure and temperature conditions induce a phase transition between supercritical $\mathrm{scCO} 2$ and subcritical gaseous $\mathrm{CO}_{2}\left(\mathrm{gCO}_{2}\right)$. The group went on to attempt reproducing experimentally vesicle formation with a lipid in a water $/ \mathrm{CO}_{2}$ system (Mayer et al. 2015).

Lipidic vesicle models require specific conditions allowing the vesicles to emerge and persist long enough, including a continuous flow of matter and energy and the possibility for the waste products to be diluted in an open milieu so that the system is not hindered by their increasing concentration (Tessera 2009, 2011). The serpentinite-hosted Lost City Hydrothermal Field (Kelley et al. 2005) is a place that has all these conditions. At high temperatures, lipid compounds can be produced by aqueous Fischer-Tropsch-type synthesis (Rushdi \& Simoneit 2001). Such abiogenic production of short-chain hydrocarbons was found at this site (Proskurowski et al. 2008). Vesicles with membranes composed of bi-layers from mixtures of amphiphilic and hydrophobic molecules could have formed from the organic compounds present locally at high concentrations. However, the stability of bilayer lipidic membranes at high 
pressure and temperature is questionable as bilayers formed of simple amphiphiles are extremely fragile at high $\mathrm{pH}$, ionic strength and high temperatures (Deamer et al. 2002; Maurer et al. 2009; Tessera 2011).

Recent work by a team of researchers at the University of Strasbourg (France) provides a credible scenario for the origin of life. They showed that the dynamics of synthetic reactions could be enhanced by compartmentalization in micrometresized droplets. The enhancement occurs due to the fact that the reactants are adsorbed to the droplet surface, react and diffuse back into the interior of the droplet. The surface tension inside the droplets drives the formation of bonds between the reactants. As a model system, they used the reversible reaction of a non-fluorescent amine; (1) with a very weakly fluorescent aldehyde, (2) to form a fluorescent imine and (3) in water (Fallah-Araghi et al. 2014). The choice of non-fluorescent reactants and fluorescent product allowed for easy visualization of the chemical reaction using fluorescence imaging. Indeed, the compartmentalization of the primordial soup into vesicles is thought to have favoured chemical synthesis that resulted in the emergence of primitive life forms.

Membranes can self-assemble into vesicular structures when small amphiphilic molecules spontaneously associate by hydrophobic interactions. Studies have demonstrated that fatty acids spontaneously assemble into bilayer membranes, building vesicles able to grow by incorporation of free lipid molecules and divide (Dworkin et al. 2001; Deamer et al. 2002; Hanczyc et al. 2003). Simple fatty acid vesicles, studied as models of ancient protocells, undergo shear- induced division when their surface to volume ratio is artificially increased by addition of fatty acids (Zhu \& Szostak 2009). Bacterial mutants with increased lipid synthesis and excess membrane production also show a physical mode of division (Mercier et al. 2013). Under primordial conditions, this increased fatty acid concentration may have been achieved by evaporation in arid, vapour-dominated geothermal fields that have been identified as plausible hatcheries for the emergence of cells (Mulkidjanian et al. 2012). Mineral surfaces, such as montmorillonite, also stimulate the formation of lipid vesicles (Hanczyc et al. 2007). Vesicles encapsulating RNA have been shown to grow preferentially by lipid capture at the expense of empty vesicles (Chen et al. 2004; Chen \& Szostak 2004). The osmotic pressure is higher inside RNA-containing vesicles due to the counter ions screening the negative charges of RNA. This osmotic pressure is counterbalanced by membrane tension, driving the uptake of fatty acids. At an early stage, this mechanism could have favoured vesicles containing charged molecules, such as ribose phosphate and/or polyphosphate, over those containing neutral molecules. Later on, the encapsulation of RNA replicators would have induced a primitive form of competition between the first RNA cells, since those containing more efficient replicators would have grown faster (Chen et al. 2004; Forterre \& Gribaldo 2007). Finally, vesicle membrane growth generates a trans-membrane $\mathrm{pH}$ gradient (Chen \& Szostak 2004; Forterre \& Gribaldo 2007), suggesting that some universal features of the living world could have their origin in fundamental physicochemical features.

\section{Conclusions}

EMVs have been implicated in many aspects of cellular life in all three domains. In particular the role of EMVs in intercellular communication is currently receiving much attention. Virus-infected cells proved useful in early studies to elucidate the role of EMV release in inter-cellular communication. The convergence of EMV biogenesis and certain aspects of viral assembly and release pathways suggests a possible viral origin of the EMV system or perhaps of an evolutionary conserved system of virus-vesicle co-dependence.

The fact that release of EMVs is a process conserved in all three domains of life implies an important evolutionary link, one that possibly dates back to the LUCA. It is widely believed that the cytoplasm evolved inside a primordial lipid vesicle. On early Earth the key components of the primitive cell were a genome, a metabolic system and the cell membrane. Indeed, a membrane-protected micro-environment would have been a key to the survival of spontaneous molecular systems and efficient metabolic systems. Efforts to synthesize model protocells encapsulating self-replicating molecules and metabolic systems may one day enable us to test these hypotheses and gain a better understanding into the origin of life.

\section{Acknowledgements}

P. F and S. G were supported by an ERC grant from the European Union's Seventh Framework Program (FP/ 2007-2013)/Project EVOMOBIL.

\section{References}

Abrescia, N.G., Bamford, D.H., Grimes, J.M. \& Stuart, D.I. (2012). Structure unifies the viral universe. Annu. Rev. Biochem. 81, 795-822.

Albers, S.V. \& Meyer, B.H. (2011). The archaeal cell envelope. Nat. Rev. Microbiol. 9(6), 414-426.

Aldick, T., Bielaszewska, M., Uhlin, B.E., Humpf, H.U., Wai, S.N. \& Karch, H. (2009). Vesicular stabilization and activity augmentation of enterohaemorrhagic Escherichia coli haemolysin. Mol. Microbiol. 71, 1496-1508.

Beveridge, T.J. (1999). Structures of gram-negative cell walls and their derived membrane vesicles. J. Bacteriol. 181(16), 4725-4733.

Beyer, C. \& Pisetsky, D.S. (2010). The role of microparticles in the pathogenesis of rheumatic diseases. Nat. Rev. Rheumatol. 6(1), 21-29.

Biller, S.J., Schubotz, F., Roggensack, S.E., Thompson, A.W., Summons, R. E. \& Chisholm, S.W. (2014). Bacterial vesicles in marine ecosytems. Science 10;343(6167), 183-186.

Brown, L., Kessler, A., Cabezas-Sanchez, P., Luque-Garcia, J.L. \& Casadevall, A. (2014). Extracellular vesicles produced by the Grampositive bacterium Bacillus subtilis are disrupted by the lipopeptide surfactin. Mol. Microbiol. 93, 183-198.

Camussi, G., Deregibus, M.C., Bruno, S., Grange, C., Fonsato, V. \& Tetta, C. (2011). Exosome/microvesicle-mediated epigenetic reprogramming of cells. Am. J. Cancer Res. 1(1), 98-110.

Charlebois, R.L. \& Doolittle, W.F. (2004). Computing prokaryotic gene ubiquity: rescuing the core from extinction. Genome Res. 14(12), 2469-2477.

Chen, I.A. \& Szostak, J.W. (2004). Membrane growth can generate a transmembrane $\mathrm{pH}$ gradient in fatty acid vesicles. Proc. Natl. Acad. Sci. USA 101, 7965-7970.

Chen, I.A., Roberts, R.W. \& Szostak, J.W. (2004). The emergence of competition between model protocells. Science 305, 1474-1476. 
Cocucci, E., Racchetti, G. \& Meldolesi, J. (2009). Shedding microvesicles: artefacts no more. Trends Cell Biol. 19(2), 43-51.

Deamer, D., Dworkin, J.P., Sandford, S.A., Bernstein, M.P. \& Allamandola, L.J. (2002). The first cell membranes. Astrobiology 2(4), 371-381.

Deamer, D.W. (1997). The first living systems: a bioenergetic perspective. Microbiol. Mol. Biol. Rev. 61(2), 239-261.

Deatherage, B.L. \& Cookson, B.T. (2012). Membrane vesicle release in bacteria, eukaryotes, and archaea: a conserved yet under appreciated aspect of microbial life. Infect. Immun. 80(6), 1948-1957.

Deich, R.A. \& Hoyer, L.C. (1982). Generation and release of DNA-binding vesicles by Haemophilus influenzae during induction and loss of competence. J. Bacteriol. 152, 855-864.

Delaye, L., Becerra, A. \& Lazcano, A. (2005). The last common ancestor: what's in a name? Orig. Life Evol. Biosph. 35, 537-554.

Del Conde, I., Shrimpton, C.N., Thiagarajan, P. \& López, J.A. (2005). Tissue-factor-bearing microvesicles arise from lipid rafts and fuse with activated platelets to initiate coagulation. Blood 106, 1604-1611.

Dorward, D.W., Garon, C.F. \& Judd, R.C. (1989). Export and intercellular transfer of DNA via membrane blebs of Neisseria gonorrhoeae. J. Bacteriol. 171, 2499-2505.

Dworkin, J., Deamer, D., Sandford, S. \& Allamandola, L. (2001). Selfassembling amphiphilic molecules: synthesis in simulated interstellar/ precometary ices. Proc. Natl. Acad. Sci. USA 98(3), 815-819.

El Andaloussi, S., Mäger, I., Breakefield, X.O. \& Wood, M.J. (2013). Extracellular vesicles: biology and emerging therapeutic opportunities. Nat. Rev. Drug Discov. 12(5), 347-357.

Ellis, T.N. \& Kuehn, M.J. (2010). Virulence and immunomodulatory roles of bacterial outer membrane vesicles. Microbiol. Mol. Biol. Rev. 74, 81-94.

Ellen, A.F. et al. (2009). Proteomic analysis of secreted membrane vesicles of Archaeal Sulfolobus species reveals the presence of endosome sorting complex components. Extremophiles 13, 67-79.

Ellen, A.F., Zolghadr, B., Driessen, A.M. \& Albers, S.V. (2010). Shaping the archaeal cell envelope. Archaea 2010, 608243-608256.

Fallah-Araghi, A., Meguellati, K., Baret, J.C., El Harrak, A., Mangeat, T., Karplus, M., Ladame, S., Marques, C.M. \& Griffiths, A.D. (2014). Enhanced chemical synthesis at soft interfaces: a universal reactionadsorption mechanism in microcompartments. Phys. Rev. Lett. 112(2), 028301.

Ferris, J.P., Hill, A.R. Jr., Liu, R. \& Orgel, L.E. (1996). Synthesis of long prebiotic oligomers on mineral surfaces. Nature 381(6577), 59-61.

Forterre, P. (2006). The origin of viruses and their possible roles in major evolutionary transitions. Virus Res. 117(1), 5-16.

Forterre, P. (2010). Giant viruses: conflicts in revisiting the virus concept. Intervirology 53(5), 362-378.

Forterre, P. \& Gribaldo, S. (2007). The origin of modern terrestrial life. HFSP J. 1(3), 156-168.

Forterre, P. \& Krupovic, M. (2012). The origin of virions and virocells: the escape hypothesis revisited. In Viruses: Essential Agents of Life, ed. G. Witzany, pp. 43-60. Springer Science and Business Media Dordrecht, The Netherlands.

Forterre, P., Soler, N., Krupovic, M., Marguet, E. \& Ackermann, H.W. (2013). Fake virus particles generated by fluorescence microscopy. Trends Microbiol. 21(1), 1-5.

Forterre, P., Krupovic, M. \& Prangishvili, D. (2014). Cellular domains and viral lineages. Trends Microbiol. 22(10), 554-558.

Fuerst, J.A. \& Sagulenko, E. (2011). Beyond the bacterium: planctomycetes challenge our concepts of microbial structure and function. Nat. Rev. Microbiol. 9(6), 403-413.

Gatti, S., Bruno, S., Deregibus, M.C., Sordi, A., Cantaluppi, V., Tetta, C. \& Camussi, G. (2011). Microvesicles derived from human adult mesenchymal stem cells protect against ischaemia-reperfusion-induced acute and chronic kidney injury. Nephrol. Dial. Transplant 26, 14741483.

Gaudin, M., Gauliard, E., Schouten, S., Houel-Renault, L., Lenormand, P., Marguet, E. \& Forterre, P. (2013). Hyperthermophilic archaea produce membrane vesicles that can transfer DNA. Environ. Microbiol. Rep. 5(1), $109-116$.
Gaudin, M., Krupovic, M., Marguet, E., Gauliard, E., Cvirkaite-Krupovic, V., Le Cam, E., Oberto, J. \& Forterre, P. (2014). Extracellular membrane vesicles harbouring viral genomes. Environ. Microbiol. 16(4), 1167-1175.

Gould, S.J. \& Raposo, G. (2013). As we wait: coping with an imperfect nomenclature for extracellular vesicles. J. Extracell. Vesicles 15, 2-5.

Gould, S.J., Booth, A.M. \& Hildreth, J.E. (2003). The Trojan exosome hypothesis. Proc. Natl. Acad. Sci. USA 100(19), 10592-10597.

Gurung, M., Moon, D.C., Choi, C.W., Lee, J.H., Bae, Y.C., Kim, J., Lee, Y. C., Seol, S.Y., Cho, D.T., Kim, S.I. \& Lee, J.C. (2011). Staphylococcus aureus produces membrane-derived vesicles that induce host cell death. PLOS ONE 6(11), e27958.

György, B., Szabó, T.G., Pásztói, M., Pál, Z., Misják, P., Aradi, B., László, V., Pállinger, E., Pap, E., Kittel, A., Nagy, G., Falus, A. \& Buzás, E.I. (2011). Membrane vesicles, current state-of-the-art: emerging role of extracellular vesicles. Cell Mol. Life Sci. 68, 667-688.

Hanczyc, M.M., Fujikawa, S.M. \& Szostak, J.W. (2003). Experimental models of primitive cellular compartments: encapsulation, growth, and division. Science 302, 618-622.

Hanczyc, M.M., Mansy, S.S. \& Szostak, J.W. (2007). Mineral surface directed membrane assembly. Orig. Life Evol. Biosph. 37, 67-82.

Harris, J.K., Kelley, S.T., Spiegelman, G.B. \& Pace, N.R. (2003). The genetic core of the universal ancestor. Genome Res. 13, 407-412.

Horstman, A.L. \& Kuehn, M.J. (2000). Enterotoxigenic Escherichia coli secretes active heat labile enterotoxin via outer membrane vesicles. J. Biol. Chem. 275(17), 12489-12496.

Huber, H., Hohn, M.J., Rachel, R., Fuchs, T., Wimmer, V.C. \& Stetter, K.O. (2002). A new phylum of Archaea represented by a nanosized hyperthermophilic symbiont. Nature 417, 63-67.

Inal, J.M., Kosgodage, U., Azam, S., Stratton, D., Antwi-Baffour, S. \& Lange, S. (2013). Blood/plasma secretome and microvesicles. Biochim. Biophys. Acta 1834(11), 2317-2325.

Izquierdo-Useros, N., Puertas, M.C., Borràs, F.E., Blanco, J. \& MartinezPicado, J. (2011). Exosomes and retroviruses: the chicken or the egg? Cell Microbiol. 13(1), 10-17.

Jalasvuori, M. \& Bamford, J.K. (2008). Structural co-evolution of viruses and cells in the primordial world. Orig. Life Evol. Biosph. 38(2), 165-181.

Jekely, G. (2006). Did the last common ancestor have a biological membrane? Biol. Direct. 1, 35.

Joyce, G.F. (1991). The rise and fall of the RNA world. New Biol. 3(4), 399-407.

Kadurugamuwa, J.L. \& Beveridge, T.J. (1997). Natural release of virulence factors in membrane vesicles by Pseudomonas aeruginosa and the effect of aminoglycoside antibiotics on their release. J. Antimicrob. Chemother. 40, 615-621.

Kanavarioti, A., Monnard, P.A. \& Deamer, D.W. (2001). Eutectic phases in ice facilitate nonenzymatic nucleic acid synthesis. Astrobiology 1(3), 271-281.

Keller, S., Rupp, C., Stoeck, A., Runz, S., Fogel, M., Lugert, S., Hager, H. D., Abdel-Bakky, M.S., Gutwein, P. \& Altevogt, P. (2007). CD24 is a marker of exosomes secreted into urine and amniotic fluid. Kidney Int. 72, 1095-1102.

Kelley, D.S. et al. (2005). A serpentinite-hosted ecosystem: the Lost City hydrothermal field. Science 307, 1428-1434.

Kesty, N.C., Mason, K.M., Reedy, M., Miller, S.E. \& Kuehn, M.J. (2004). Enterotoxigenic Escherichia coli vesicles target toxin delivery into mammalian cells. EMBO J. 23, 4538-4549.

Klingl, A. (2014). S-layer and cytoplasmic membrane - exceptions from the typical archaeal cell wall with a focus on double membranes. Front. Microbiol. 5, 624.

Koch, A.L. (1985). Primeval cells: possible energy-generating and celldivision mechanisms. J. Mol. Evol. 21, 270-277.

Koonin, E.V. (2003). Comparative genomics, minimal gene-sets and the last universal common ancestor. Nat. Rev. Microbiol. 1, 127-136.

Kosaka, N., Izumi, H., Sekine, K. \& Ochiya, T. (2010). microRNA as a new immune-regulatory agent in breast milk. Silence 1, 7-14.

Kristensen, D.M., Mushegian, A.R., Dolja, V.V. \& Koonin, E.V. (2010). New dimensions of the virus world discovered through metagenomics. Trends Microbiol. 18(1), 11-19. 
Kuehn, M.J. \& Kesty, N.C. (2005). Bacterial outer membrane vesicles and the host-pathogen interaction. Genes Dev. 19, 2645-2655.

Kulp, A. \& Kuehn, M.J. (2010). Biological functions and biogenesis of secreted bacterial outer membrane vesicles. Annu. Rev. Microbiol. 64 , 163-184.

Küper, U., Meyer, C., Müller, V., Rachel, R. \& Huber, H. (2010). Energized outer membrane and spatial separation of metabolic processes in the hyperthermophilic Archaeon Ignicoccus hospitalis. Proc. Natl. Acad. Sci. USA 107(7), 3152-3156.

Lakkaraju, A. \& Rodriguez-Boulan, E. (2008). Itinerant exosomes: emerging roles in cell and tissue polarity. Trends Cell Biol. 18(5), 199-209.

Lee, E.Y. et al. (2009). Gram-positive bacteria produce membrane vesicles: proteomics-based characterization of Staphylococcus aureus-derived membrane vesicles. Proteomics 9, 5425-5436.

Loeb, M.R. \& Kilner, J. (1978). Release of a special fraction of the outer membrane from both growing and phage T4-infected Escherichia coli B. Biochim. Biophys. Acta 514(1), 117-127.

Lonhienne, T.G., Sagulenko, E., Webb, R.I., Lee, K.C., Franke, J., Devos, D.P., Nouwens, A., Carroll, B.J. \& Fuerst, J.A. (2010). Endocytosis like protein uptake in the bacterium Gemmata obscuriglobus. Proc. Natl. Acad. Sci. USA 20;107(29), 12883-12888.

MacDonald, I.A. \& Kuehn, M.J. (2013). Stress-induced outer membrane vesicle production by Pseudomonas aeruginosa. J. Bacteriol. 195, 29712981.

Maldonado, R., Wei, R., Kachlany, S.C., Kazi, M. \& Balashova, N.V. (2011). Cytotoxic effects of Kingella kingae outer membrane vesicles on human cells. Microb. Pathog. 51, 22-30.

Manning, A.J. \& Kuehn, M.J. (2011). Contribution of bacterial outer membrane vesicles to innate bacterial defense. BMC Microbiol. 1(11), 258

Marguet, E., Gaudin, M., Gauliard, E., Fourquaux, I., le Blond du Plouy, S., Matsui, I. \& Forterre, P. (2013). Membrane vesicles, nanopods and/or nanotubes produced by hyperthermophilic archaea of the genus Thermococcus. Biochem. Soc. Trans. 41(1), 436-442.

Marsh, M. \& Helenius, A. (2006). Virus entry: open sesame. Cell 124(4), 729-740.

Marsollier, L. et al. (2007). Impact of Mycobacterium ulcerans biofilm on transmissibility to ecological niches and Buruli ulcer pathogenesis. PLoS Pathog. 4;3(5), e62.

Mathivanan, S., Ji, H. \& Simpson, R.J. (2010). Exosomes: extracellular organelles important in intercellular communication. J. Proteomics 10;73 (10), 1907-1920.

Maurer, S.E., Deamer, D.W., Boncella, J.M. \& Monnard, P.A. (2009). Chemical evolution of amphiphiles: glycerol monoacyl derivatives stabilize plausible prebiotic membranes. Astrobiology 9, 979-987.

Mayer, C., Schreiber, U. \& Dávila, M.J. (2015). Periodic vesicle formation in tectonic fault zones - as an ideal scenario for molecular evolution. Orig. Life Evol. Biosph. 45(1-2), 139-148.

McBroom, A.J. \& Kuehn, M.J. (2007). Release of outer membrane vesicles by Gram-negative bacteria is a novel envelope stress response. Mol. Microbiol. 63, 545-558.

Meckes, D.G. Jr. \& Raab-Traub, N. (2011). Microvesicles and viral infection. J. Virol. 85(24), 12844-12854.

Mercier, R., Kawai, Y. \& Errington, J. (2013). Excess membrane synthesis drives a primitive mode of cell proliferation. Cell 152(5), 997-1007.

Michael, A., Bajracharya, S.D., Yuen, P.S., Zhou, H., Star, R.A., Illei, G.G. \& Alevizos, I. (2010). Exosomes from human saliva as a source of micro RNA biomarkers. Oral Dis. 16, 34-38.

Mulkidjanian, A.Y., Bychkov, A.Y., Dibrova, D.V., Galperin, M.Y. \& Koonin, E.V. (2012). Origin of first cells at terrestrial, anoxic geothermal fields. Proc. Natl. Acad. Sci. USA 109(14), 821-830.

Näther, D.J. \& Rachel, R. (2004). The outer membrane of the hyperthermophilic archaeon Ignicoccus: dynamics, ultrastructure and composition. Biochem. Soc. Trans. 32(Pt 2), 199-203.

Pegtel, D.M., Cosmopoulos, K., Thorley-Lawson, D.A., van Eijndhoven, M. A., Hopmans, E.S., Lindenberg, J.L., de Gruijl, T.D., Würdinger, T. \& Middeldorp, J.M. (2010). Functional delivery of viral miRNAs via exosomes. Proc. Natl. Acad. Sci. USA 107(14), 6328-6333.
Pelchen-Matthews, A., Raposo, G. \& Marsh, M. (2004). Endosomes, exosomes and Trojan viruses. Trends Microbiol. 12(7), 310-316.

Pereto, J., Lopez-Garcia, P. \& Moreira, D. (2004). Ancestral lipid biosynthesis and early membrane evolution. Trends Biochem. Sci. 29, 469-477.

Pérez-Cruz, C., Carrión, O., Delgado, L., Martinez, G., López-Iglesias, C. \& Mercade, E. (2013). New type of outer membrane vesicle produced by the Gram-negative bacterium Shewanella vesiculosa M7T: implications for DNA content. Appl. Environ. Microbiol. 79(6), 1874-1881.

Pérez-Cruz, C., Delgado, L., López-Iglesias, C. \& Mercade, E. (2015). Outer-inner membrane vesicles naturally secreted by gram-negative pathogenic bacteria. PLOS ONE 12;10(1), e0116896.

Perras, A.K. et al. (2014). Grappling archaea: ultrastructural analyses of an uncultivated, cold-loving archaeon, and its biofilm. Front. Microbiol. 5(5), 397.

Pina, M., Bize, A., Forterre, P. \& Prangishvili, D. (2011). The archeoviruses. FEMS Microbiol Rev. 35(6), 1035-1054.

Pisitkun, T., Shen, R.F. \& Knepper, M.A. (2004). Identification and proteomic profiling of exosomes in human urine. Proc. Natl. Acad. Sci. USA 101, 13368-13373.

Prados-Rosales, R., et al. (2011). Mycobacteria release active membrane vesicles that modulate immune responses in a TLR2-dependent manner in mice. J. Clin. Invest. 121(4), 1471-1483.

Prangishvili, D., Holz, I., Stieger, E., Nickell, S., Kristjansson, J.K. \& Zillig, W. (2000). Sulfolobicins, specific proteinaceous toxins produced by strains of the extremely thermophilic archaeal genus Sulfolobus. J. Bacteriol. 182 (10), 2985-2988.

Proskurowski, G., Lilley, M.D., Seewald, J.S., Fruh-Green, G.L., Olson, E. J., Lupton, J.E., Sylva, S.P. \& Kelley, D.S. (2008). Abiogenic hydrocarbon production at lost city hydrothermal field. Science 319, 604-607.

Rak, J. \& Guha, A. (2012). Extracellular vesicles - vehicles that spread cancer genes. Bioessays 34, 489-497.

Raposo, G. \& Stoorvogel, W. (2013). Extracellular vesicles: exosomes, microvesicles, and friends. J. Cell Biol. 200(4), 373-383.

Raposo, G., Nijman, H.W., Stoorvogel, W., Liejendekker, R., Harding, C. V., Melief, C.J. \& Geuze, H.J. (1996). B lymphocytes secrete antigen-presenting vesicles. J. Exp. Med. 183(3), 1161-1172.

Ratajczak, J., Miekus, K., Kucia, M., Zhang, J., Reca, R., Dvorak, P. \& Ratajczak, M.Z. (2006). Embryonic stem cell-derived microvesicles reprogram hematopoietic progenitors: evidence for horizontal transfer of mRNA and protein delivery. Leukemia 20, 847-856.

Renelli, M., Matias, V., Lo, R.Y. \& Beveridge, T.J. (2004). DNA- containing membrane vesicles of Pseudomonas aeruginosa PAO1 and their genetic transformation potential. Microbiology 150, 2161-2169.

Rivera, J., Cordero, R.J., Nakouzi, A.S., Frases, S., Nicola, A. \& Casadevall, A. (2010). Bacillus anthracis produces membrane- derived vesicles containing biologically active toxins. Proc. Natl. Acad. Sci. USA 107, 19002-19007.

Robertson, M.P. \& Miller, S.L. (1995). An efficient prebiotic synthesis of cytosine and uracil. Nature 375(6534), 772-4. Erratum in: Nature 1995 Sep 21;377(6546):257.

Rohwer, F. \& Thurber, R.V. (2009). Viruses manipulate the marine environment. Nature 459(7244), 207-212.

Rushdi, A.I. \& Simoneit, B.R. (2001). Lipid formation by aqueous Fischer-Tropsch-type synthesis over a temperature range of 100 to 400 degrees C. Orig. Life Evol. Biosph. 31, pp. 103-118.

Schooling, S.R. \& Beveridge, T.J. (2006). Membrane vesicles: an overlooked component of the matrices of biofilms. J. Bacteriol. 188(16), 5945-5957.

Schooling, S.R., Hubley, A. \& Beveridge, T.J. (2009). Interactions of DNA with biofilm-derived membrane vesicles. J. Bacteriol. 191(13), 4097-4102.

Schreiber, U., Locker-Grütjen, O. \& Mayer, C. (2012). Hypothesis: origin of life in deep-reaching tectonic faults. Orig. Life Evol. Biosph. 42, 47-54.

Schrempf, H., Koebsch, I., Walter, S., Engelhardt, H. \& Meschke, H. (2011). Extracellular Streptomyces vesicles: amphorae for survival and defence. Microb. Biotechnol. 4(2), 286-299.

Segré, D., Ben-Eli, D., Deamer, D.W. \& Lancet, D. (2001). The lipid world. Orig. Life Evol. Biosph. 31(1-2), 119-145. 
Soler, N., Marguet, E., Verbavatz, J.-M. \& Forterre, P. (2008). Virus-like vesicles and extracellular DNA produced by hyperthermophilic archaea of the order Thermococcales. Res. in Microbiol. 159(5), 390-399.

Soler, N., Gaudin, M., Marguet, E. \& Forterre, P. (2011). Plasmids, viruses and virus-like membrane vesicles from Thermococcales. Biochem. Soc. Trans. 39(1), 36-44.

Soler, N., Krupovic, M., Marguet, E. \& Forterre, P. (2015). Membrane vesicles in natural environments: a major challenge in viral ecology. ISME J. 9, 793-796.

Sowerby, S.J. \& Petersen, G.B. (2002). Life before RNA. Astrobiology 2(3), 231-239.

Stribling, R. \& Miller, S.L. (1991). Template-directed synthesis of oligonucleotides under eutectic conditions. J. Mol. Evol. 32, 289-295.

Suttle, C. (2005). Crystal ball. The viriosphere: the greatest biological diversity on Earth and driver of global processes. Environ. Microbiol. 7(4), 481-482.

Tessera, M. (2009). Life began when evolution began: a lipidic vesicle-based scenario. Orig. Life Evol. Biosph. 39, 559-564.

Tessera, M. (2011). Origin of evolution versus origin of life: a shift of paradigm. Int. J. Mol. Sci. 12(6), 3445-3458.
Thay, B., Wai, S.N. \& Oscarsson, J. (2013). Staphylococcus aureus $\alpha$-toxin-dependent induction of host cell death by membrane-derived vesicles. PLOS ONE 8(1), e54661.

Théry, C., Ostrowski, M. \& Segura, E. (2009). Membrane vesicles as conveyors of immune responses. Nature Rev. Immunol. 9, 581-593.

Valadi, H., Ekström, K., Bossios, A., Sjöstrand, M., Lee, J.J. \& Lötvall, J.O. (2007). Exosome mediated transfer of mRNAs and microRNAs is a novel mechanism of genetic exchange between cells. Nat. Cell Biol. 9(6), 654-659.

van der Pol, E., Böing, A.N., Harrison, P., Sturk, A. \& Nieuwland, R. (2012). Classification, functions, and clinical relevance of extracellular vesicles. Pharmacology 64(3), 676-705.

Wächtershäuser, G. (1988). Before enzymes and templates: theory of surface metabolism. Microbiol. Rev. 52(4), 452-484.

Waters, E. et al. (2003). The genome of Nanoarchaeum equitans: insights into early archaeal evolution and derived parasitism. Proc. Natl. Acad. Sci. USA 100(22), 12984-12988.

Zhu, T.F. \& Szostak, J.W. (2009). Preparation of large monodisperse vesicles. PLoS ONE 4(4), e5009. 